\title{
Phase transitions and hygroscopic growth of aerosol particles containing humic acid and mixtures of humic acid and ammonium sulphate
}

\author{
C. L. Badger ${ }^{1}$, I. George ${ }^{2}$, P. T. Griffiths ${ }^{1}$, C. F. Braban ${ }^{1}$, R. A. Cox ${ }^{1}$, and J. P. D. Abbatt ${ }^{2}$ \\ ${ }^{1}$ Centre for Atmospheric Science, Dept. of Chemistry, Lensfield Road, University of Cambridge, Cambridge, CB2 1EW, UK \\ ${ }^{2}$ Department of Chemistry, University of Toronto, ON, M5S 3H6, Canada
}

Received: 22 June 2005 - Published in Atmos. Chem. Phys. Discuss.: 5 October 2005

Revised: 13 January 2006 - Accepted: 24 January 2006 - Published: 6 March 2006

\begin{abstract}
The phase transitions and hygroscopic growth of two humic acid aerosols (Aldrich sodium salt and Leonardite Standard (IHSS)) and their mixtures with ammonium sulphate have been investigated using a combination of two techniques, Fourier transform infra-red (FTIR) spectroscopy and tandem differential mobility analysis (TDMA). A growth factor of 1.16 at $85 \%$ relative humidity $(R H)$ was found for the Aldrich humic acid which can be regarded as an upper limit for growth factors of humic-like substances (HULIS) found in atmospheric aerosol and is significantly smaller than that of typical atmospheric inorganics. We find that the humic acid aerosols exhibit water uptake over all relative humidities with no apparent phase changes, suggesting that these aerosols readily form supersaturated droplets. In the mixed particles, the humic acid component decreases the deliquescence relative humidity (DRH) and increases the efflorescence relative humidity (ERH) of the ammonium sulphate component, and there is some degree of water uptake prior to ammonium sulphate deliquescence. In addition, at low RH, the FTIR spectra show that the ammonium is present in a different chemical environment in the mixed aerosols than in crystalline ammonium sulphate, perhaps existing as a complex with the humic materials. The growth factors of the mixed aerosols are intermediate between those of the singlecomponent aerosols and can be predicted assuming that the inorganic and organic fractions take up water independently.
\end{abstract}

Correspondence to: J. P. D. Abbatt

(jabbatt@chem.utoronto.ca)

\section{Introduction}

Organic matter can contribute up to $90 \%$ of the total mass of the fine fraction of tropospheric aerosol (Kanakidou et al. (2005) and references therein). Typically only $10-15 \%$ of this can be identified on a molecular level (Puxbaum et al., 2000). Using an ion-chromatography technique, Fuzzi et al. (2001) have separated the water soluble organic compounds (WSOC) into three main classes based on their acid/base character: i) neutral compounds; ii) mono/di carboxylic acids; iii) polycarboxylic acids, allowing $\sim 90 \%$ of the organic matter to be classified. The polycarboxylic fraction can account for between 20 and 50\% of WSOC (McFiggans et al., 2005) and consists of molecules that have similar molecular weights and functional groups to naturally occurring humic or fulvic acids, hence they are often referred to as humic-like substances (HULIS) in the literature. $\mathrm{Hu}$ mic and fulvic acids are a heterogeneous mixture of chemicals containing mainly carboxylic, hydroxyl and carbonyl functional groups. They are a major component of soils, formed through the decomposition of plant and animal materials. Limbeck et al. (2003) have shown that primary sources, e.g. biomass burning and dust from wind erosion, alone cannot account for the observed levels of HULIS in ambient aerosol. Possible secondary sources include the heterogeneous condensation reaction of the oxidation products of isoprene or $\alpha$-pinene in the presence of a sulphuric acid catalyst (Limbeck et al., 2003) or the photo-oxidation of anthropogenic and biogenic precursors (Kalberer et al., 2004; Baltensperger et al., 2005). 
Recent studies have investigated the effect of smaller organics, such as dicarboxylic acids, on the physical properties of inorganic aerosol (Choi and Chan, 2002; Prenni et al., 2003; Braban and Abbatt, 2004; Marcolli et al., 2004) and these are now beginning to be incorporated into thermodynamic models of mixed inorganic-organic particles (Clegg et al., 2001; Topping et al., 2005). These studies are now being extended to consider the effects of macromolecular organic compounds. Hygroscopic tandem differential mobility analysis (HTDMA) (Brooks et al., 2004; Gysel et al., 2004), electrodynamic balance (EDB) (Chan and Chan, 2003) and optical microscopy (Parsons et al., 2004) techniques have all been used to investigate the properties of humic and/or fulvic acids as proxies for atmospheric HULIS and their combinations with inorganic salts as a function of relative humidity $(R H)$. In particular, three main properties are measured: The hygroscopic growth factor, $G$, defined as the the ratio of the particle diameter at the $R H$ of the measurement $\left(D_{R H}\right)$ to the dry particle diameter $\left(D_{0}\right)$ and the phase transitions as quantified by the efflorescence (or crystallisation) relative humidity (ERH or CRH) and the deliquescence relative humidity (DRH).

For the humic and fulvic acids, these studies generally showed a small water uptake over all $R H$ with no obvious phase transitions. For mixed organic-inorganic systems, the phase transitions observed were comparable to those of the pure inorganic aerosol but growth factors were reduced. However, there is still limited data on the dependence of these properties on the mass ratio of inorganic to organic in the aerosol and only one study considered the effect of these humic and fulvic acids on the efflorescence of inorganic salts (Chan and Chan, 2003). More laboratory studies are needed before these larger organics can be accurately incorporated into thermodynamic models.

The use of Fourier transform infra-red (FTIR) spectroscopy allows phase transitions to be observed directly rather than inferring them from size or mass changes which means phase transitions can be observed in systems that exhibit almost continuous water uptake. In a previous FTIR study, the effect of malonic acid on the phase and water content of ammonium sulphate aerosols was considered (Braban and Abbatt, 2004). The position of $\mathrm{NH}_{4}^{+}$mode is dependent on the phase of the ammonium sulphate aerosol (Cziczo et al., 1997; Braban and Abbatt, 2004) and the shift in the position of this mode was used to determine the CRH and the DRH of the ammonium sulphate component of the mixed aerosol. For the mixed ammonium sulphate-malonic acid aerosols, we found that both the CRH and the DRH of the individual components were lowered in the presence of the other component. We also found that, at low $R H$, the $\mathrm{NH}_{4}^{+}$mode appeared at $\sim 1435 \mathrm{~cm}^{-1}$ in the mixed systems compared with $\sim 1420 \mathrm{~cm}^{-1}$ for solid ammonium sulphate suggesting that the $\mathrm{NH}_{4}^{+}$is present in a different chemical environment in the mixed aerosols.
Here we extend our work on malonic acid-ammonium sulphate aerosols to investigate the effect of HULIS on the phase and water content of ammonium sulphate aerosol using a combination of FTIR and TDMA techniques. Specifically the following questions will be addressed: Does continuous water uptake occur for both the single-component organic aerosols and the mixed aerosols; Does the organic component exhibit efflorescence/deliquescence behaviour and does this component affect the efflorescence/deliquescence behaviour of the ammonium sulphate; Is there any evidence for formation of new chemical species in the mixed aerosols and can the growth of the mixed aerosols be predicted on the basis of non-interacting components?

There are many commercially available humic and fulvic acids. In past studies (e.g. Chan and Chan, 2003; Brooks et al., 2004; Gysel et al., 2004; Parsons et al., 2004), little qualitative difference in behaviour has been observed depending on the exact choice of humic or fulvic acid as a proxy for atmospheric HULIS and so in this work two humic acids were chosen, the readily available Aldrich humic acid sodium salt (NaHA) and IHSS Leonardite standard humic acid (LSHA). The hygroscopic properties of these humic acids have been examined by Gysel et al. (2004) (NaHA) and Brooks et al. (2004) (LSHA).

\section{Experimental methods}

\subsection{Aerosol generation}

Aerosols for both the FTIR and TDMA systems were generated from bulk aqueous solutions using a commercial atomiser (3076, TSI). Solutions were made up from mixtures of two different humic acids (sodium salt, Aldrich, NaHA and Leonardite Standard humic acid, IHSS, LSHA) and ammonium sulphate $(99.98 \%$, Fisher) in distilled water. Solutions containing NaHA were filtered through Fisherbrand P8 filter paper, pore size 20-25 $\mu \mathrm{m}$ (FTIR experiments) or Whatman 54 filter paper, pore size 20-25 $\mu \mathrm{m}$ (TDMA experiments) prior to atomisation, to remove most of the insoluble components. The $\mathrm{pH}$ of solutions containing LSHA was adjusted to $\mathrm{pH} 7$ with the addition of $\mathrm{NaOH}$ to allow most of the LSHA to dissolve and then filtered through Whatman 1 filter paper, pore size $11 \mu \mathrm{m}$. In order to determine the composition of the filtered solutions, a small quantity of each solution was dried and the wt $\%$ of $\mathrm{N}, \mathrm{C}$ and $\mathrm{H}$ determined (ANALEST, Department of Chemistry, University of Toronto (FTIR experiments), Microanalysis, Department of Chemistry, University of Cambridge (TDMA experiments)). Elemental analysis was also carried out on the single-component humic acid and ammonium sulphate solutions.

Elemental analysis results for the solutions used in these experiments are summarised in Table 1 . The elemental analysis for ammonium sulphate is consistent with the molecular stoichiometry. The two sets of elemental analysis results for 
NaHA differ slightly due to the fact that NaHA is not a pure compound but are in general agreement with elemental analysis results from Davis et al. (1999). Errors in the measured wt $\%$ are estimated to be $\pm 1 \%$ based on the variation in the results from the two different NaHA analyses.

These results show that there is $\leq 1 \mathrm{wt} \% \mathrm{C}$ present in the ammonium sulphate and $\leq 1 \mathrm{wt} \% \mathrm{~N}$ present in the humic acid. This was used to infer the mass ratios of humic acid to ammonium sulphate in the mixed systems i.e. $\mathrm{C}$ present was due to humic acid and $\mathrm{N}$ present was due to ammonium sulphate. For example, the mass ratio of humic acid $($ mixed solutions $)=\% \mathrm{C}($ mixed solution $) / \% \mathrm{C}($ humic acid $)$ and the mass ratio ammonium sulphate (mixed solutions) $=$ $\% \mathrm{~N}$ (mixed solution)/\% N (ammonium sulphate). Aerosols formed from these solutions will be referred to by their mass ratios of humic acid to ammonium sulphate (i.e. NaHA:AS or LSHA:AS).

The $\mathrm{pH}$ of the single-component NaHA aerosol was approximately 9 ( $\mathrm{pH}$ meter, Orion 520A). It is possible that the presence of carboxylate groups (as opposed to protonated carboxylic acid groups) affects the hygroscopic properties of the humic acid. In order to investigate this effect, FTIR studies were carried out on an aerosol produced from a filtered solution of NaHA at $\mathrm{pH} 4$ (adjusted by the addition of $\mathrm{HCl}$ ). It should be noted that the $\mathrm{pH}$ of the solutions from which the aerosols are generated does not necessarily translate to the $\mathrm{pH}$ within the actual aerosol droplets. However, for the sake of simplicity, aerosols produced from the $\mathrm{pH} 4$ and $\mathrm{pH}$ 9 NaHA solutions will be referred to as $\mathrm{pH} 4 \mathrm{NaHA}$ and $\mathrm{pH}$ 9 NaHA in subsequent sections.

\subsection{Fourier Transform Infra-Red Spectroscopy}

The FTIR experimental system (Fig. 1) has been described elsewhere (Cziczo et al., 1997; Braban et al., 2003) but is summarised here. Part of the aerosol flow from the atomiser (between 0.3 and $1 \mathrm{l}(\mathrm{STP}) \mathrm{min}^{-1}$ depending on the required particle concentration) enters the aerosol flow tube system via a diffusion dryer (residence time between 12 and $40 \mathrm{~s}$ ) and the remainder is sent to a dump line. The dryer consists of a clear channel surrounded by silica gel (ACP Silica Gel 6-16 mesh) and can be bypassed depending on the experimental mode. The relative humidity $(R H)$ of the aerosol stream is then further adjusted by addition of a 21 (STP) $\min ^{-1}$ nitrogen flow, a variable fraction of which is saturated with water vapour. The flow is sent to the main aerosol flow tube via a conditioner (residence time between 6 and $8 \mathrm{~s}$ ) to allow for equilibration. Both the conditioner and the flow tube are temperature controlled. The temperature is monitored just below the optical axis using a T-type thermocouple.

IR spectra (typically averaged over 50 scans) are recorded over a length of $\sim 50 \mathrm{~cm}$ over the wavenumber range 4000 $500 \mathrm{~cm}^{-1}$ with a resolution of $4 \mathrm{~cm}^{-1}$ using an FTIR spectrometer (Bomem, MB104 with external MCT detector). The
Table 1. Summary of the elemental analysis data used to determine the ratios (by mass) of humic acid (NaHA or LSHA) to ammonium sulphate (AS) present in the filtered solutions used to generate internally mixed aerosols.

\begin{tabular}{|c|c|c|c|c|c|}
\hline \multirow{2}{*}{ Solution } & \multirow{2}{*}{ wt $\%$ solid } & \multicolumn{3}{|c|}{ Elemental Analysis } & \multirow{2}{*}{$\begin{array}{c}\text { Ratio } \\
\text { HA:AS }\end{array}$} \\
\hline & & $\mathrm{wt} \% \mathrm{C}$ & $\mathrm{wt} \% \mathrm{H}$ & $\mathrm{wt} \% \mathrm{~N}$ & \\
\hline \multicolumn{6}{|c|}{ FTIR experiments } \\
\hline NaHA, pH 9 & 4.3 & 43.9 & 3.5 & 0.7 & - \\
\hline LSHA, pH 7 & 1.7 & 49.4 & 3.8 & 1.0 & - \\
\hline AS & $\sim 25$ & 0.8 & 5.8 & 21.0 & - \\
\hline Mix 1 (NaHA) & 13.8 & 2.9 & 5.5 & 18.8 & $1: 13$ \\
\hline Mix 2 (NaHA) & 8.2 & 21.7 & 5.0 & 11.0 & $1: 1$ \\
\hline Mix 3 (NaHA) & 5.8 & 23.2 & 5.0 & 7.9 & $1.5: 1$ \\
\hline Mix 4 (LSHA) & 3.3 & 23.6 & 4.4 & 10.4 & $1: 1$ \\
\hline \multicolumn{6}{|c|}{ TDMA experiments } \\
\hline NaHA, pH 9 & 0.8 & 40.8 & 2.8 & 0.5 & - \\
\hline AS & 1.3 & 0 & 5.9 & 21.2 & - \\
\hline Mix 1 (NaHA) & 2.1 & 6.2 & 4.9 & 16.4 & $1: 5$ \\
\hline Mix 2 (NaHA) & 1.7 & 15.5 & 4.2 & 11.5 & $1: 1.5$ \\
\hline Mix 3 (NaHA) & 1.5 & 26.0 & 3.5 & 6.6 & $2: 1$ \\
\hline
\end{tabular}

$R H$ in the flow tube is measured using a separate calibration based on the integration of gas-phase water lines over the region $1710-1688 \mathrm{~cm}^{-1}$. The confidence in the $R H$ measurement is $\pm 1 \%$ (Cziczo et al., 1997; Braban et al., 2003).

Experiments were carried out in two different modes, 'efflorescence' and 'deliquescence'. During an efflorescence mode experiment, the dryer is bypassed and the relative humidity is incrementally decreased; during a deliquescence mode experiment the aerosol stream is dried to $\leq 2 \% R H$ by passing through the diffusion dryer and the relative humidity is incrementally increased. Previous experiments on this system have shown that $3-4 \mathrm{~min}$ is sufficient to allow a stabilisation of the RH. In order to cover the full range of $\mathrm{RH}$, efflorescence experiments were carried out at a temperature of $298 \mathrm{~K}$ and deliquescence experiments were carried out at a temperature of $288 \mathrm{~K}$. As the absorption due to water vapour is much stronger than that due to the aerosol, a reference spectrum of the humid $\mathrm{N}_{2}$ stream is subtracted prior to analysis in order to obtain an absorption spectrum due to the aerosol particles alone.

For all the aerosols used in the FTIR experiments, measured size distributions were approximately log-normal with $D_{p g} \approx 135 \mathrm{~nm}$ and $\sigma_{g} \approx 1.9$ at $R H<2 \%$. Typical particle number concentrations were $1 \times 10^{6} \mathrm{~cm}^{-3}$.

\subsection{Tandem Differential Mobility Analyser}

A schematic of the TDMA experimental set-up is shown in Fig. 2. All experiments were carried out at room temperature ( $293 \mathrm{~K}$ with a day to day variation of $\sim 3 \mathrm{~K}$ ). Upon leaving 


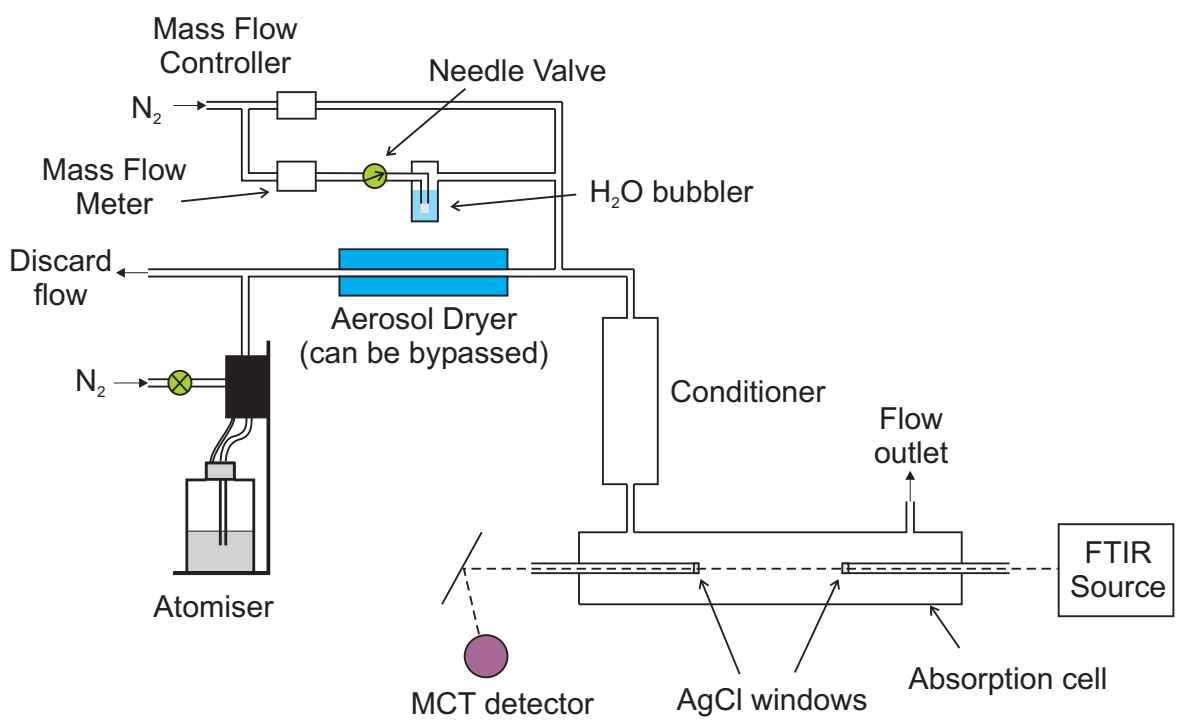

Fig. 1. Schematic of the Aerosol Flow Tube - FTIR set-up.

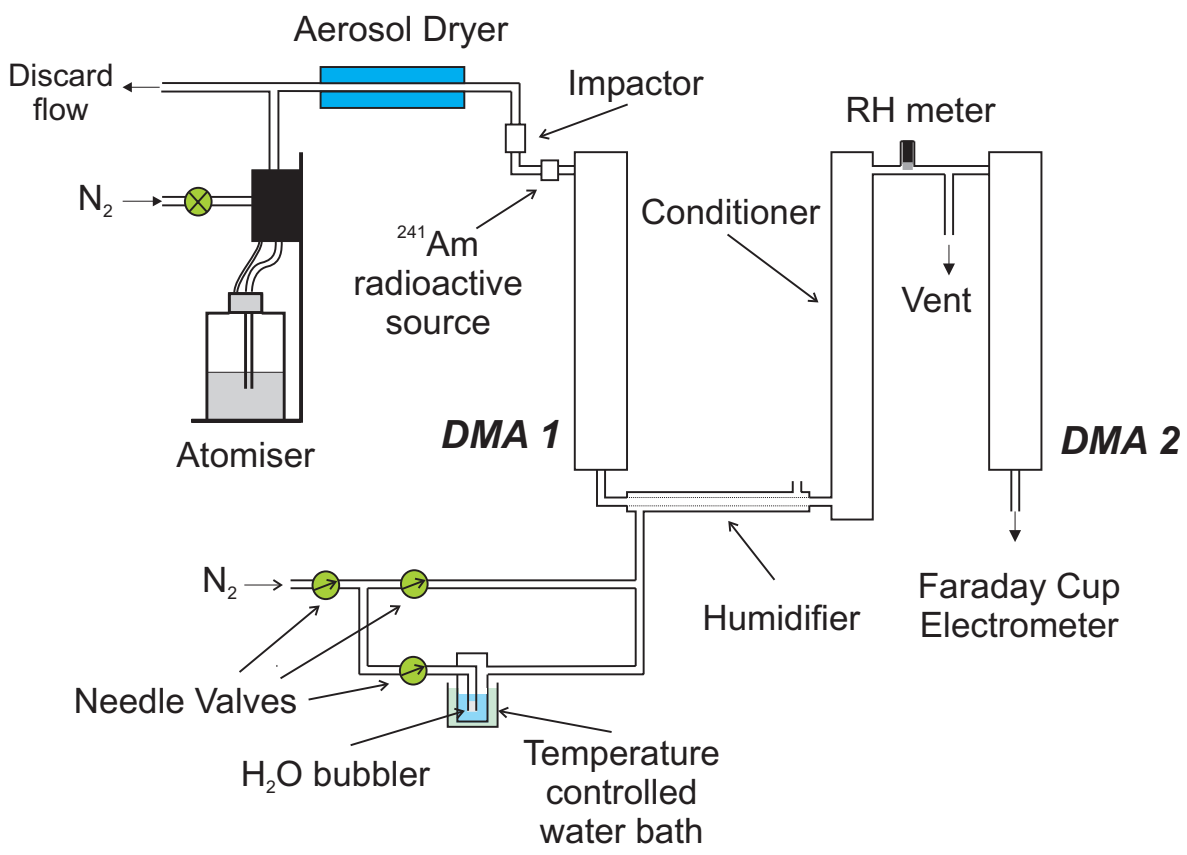

Fig. 2. Schematic of the experimental set-up for the TDMA experiments.

the atomiser, a 11 (STP) $\min ^{-1}$ aerosol flow is dried to an $R H$ of $<2 \%$ by passing through a diffusion dryer (residence time $\sim 30 \mathrm{~s}$ ). All experiments are therefore carried out in 'deliquescence' mode. Particles enter the first DMA (DMA 1, EMS-VIE 08, Hauke) and a monodisperse distribution of particles of the required diameter is selected. Experiments were carried out for both 50 and $100 \mathrm{~nm}$ diameter particles in order to assess the effect of initial particle diameter on hygroscopic growth.
The $R H$ of the size-selected aerosol is then adjusted by passing through a humidifier (Perma Pure, MH-110-24P-4) consisting of Nafion tubing around which a humidified gas stream $\left(\sim 31\right.$ (STP) $\left.\mathrm{min}^{-1}\right)$ is flowed. The Nafion tubing is permeable to water vapour which allows for an increase in the RH of the aerosol stream without dilution. The aerosol then passes through the conditioner (residence time $\sim 3 \mathrm{~min}$ ) to allow for equilibration of the aerosol particles and the size distribution is measured with the second DMA (DMA 2) and a Faraday cup electrometer (Hauke, Model FCE 08/A). The 
$R H$ of the aerosol is measured prior to entering DMA 2 by a $R H$ humitter (Vaisala, 50Y). The sheath air for DMA 2 is humidified to the same $\mathrm{RH}$ as the aerosol stream using an open sheath-flow system to prevent the aerosol particles changing size during measurement. The sheath to aerosol flow ratio is 10:1. Further details on the operation of the Hauke DMA can be found in Reischl (1991) and Winklmayr et al. (1991).

Initially, the dry size distribution was measured by passing the size-selected aerosol to the second DMA without any adjustment of the RH. The measured size distributions were found to be well-described by a log-normal function with $\sigma_{g}=1.1 \pm 0.1$. The growth of the particles was quantified using the hygroscopic growth factor, $G$, the ratio of the median diameter at the $R H$ of the measurement $\left(D_{R H}\right)$ to the dry median diameter $\left(D_{0}\right)$ as measured by DMA 2 at $R H<2 \%$. $D_{0}$ was found to be $7 \pm 2 \%$ larger than the diameter formally selected by DMA 1 . It should be noted that growth factors derived from TDMA measurements are based on the mobility-diameter which is only equivalent to the physical (or volume-equivalent) diameter in the case of spherical particles.

\section{Results}

\subsection{Ammonium sulphate}

Ammonium sulphate aerosol was used to test both the FTIR and TDMA experimental set-ups as it is the standard tropospheric aerosol proxy and has been well characterised previously (Tang and Munkelwitz, 1993; Cziczo et al., 1997; Prenni et al., 2003).

IR spectra obtained were in close agreement with those obtained by Cziczo et al. (1997) and showed both scattering and absorption features. The continuous, underlying increase in aerosol extinction with increasing frequency is due to Mie scattering of the IR beam by the aerosol particles. The water uptake and phase of the particles were quantitatively analysed as a function of $R H$ using a similar technique to those of our previous studies (Braban et al., 2003; Braban and Abbatt, 2004). The condensed-phase water band due to the $\mathrm{OH}$ stretch was integrated between 3400 and $3670 \mathrm{~cm}^{-1}$, taking into account the change in baseline due to Mie scattering. This area was normalised to the area of the sulphate absorption mode (from $1000-1200 \mathrm{~cm}^{-1}$ ) to account for any changes in particle number density (Fig. 3a).

The position of the $\mathrm{NH}_{4}^{+}$absorption mode (Fig. 3b) is diagnostic of the phase of the ammonium sulphate particles and reflects the differing chemical environments in the aqueous and solid phases. The growth curve obtained with the TDMA for ammonium sulphate aerosol is shown in Fig. 3c. From these measurements we obtain a deliquescence relative humidity (DRH) of $80 \pm 2 \%$ (shown as a dotted blue line) and an efflorescence relative humidity (ERH) of $34 \pm 2 \%$ (shown

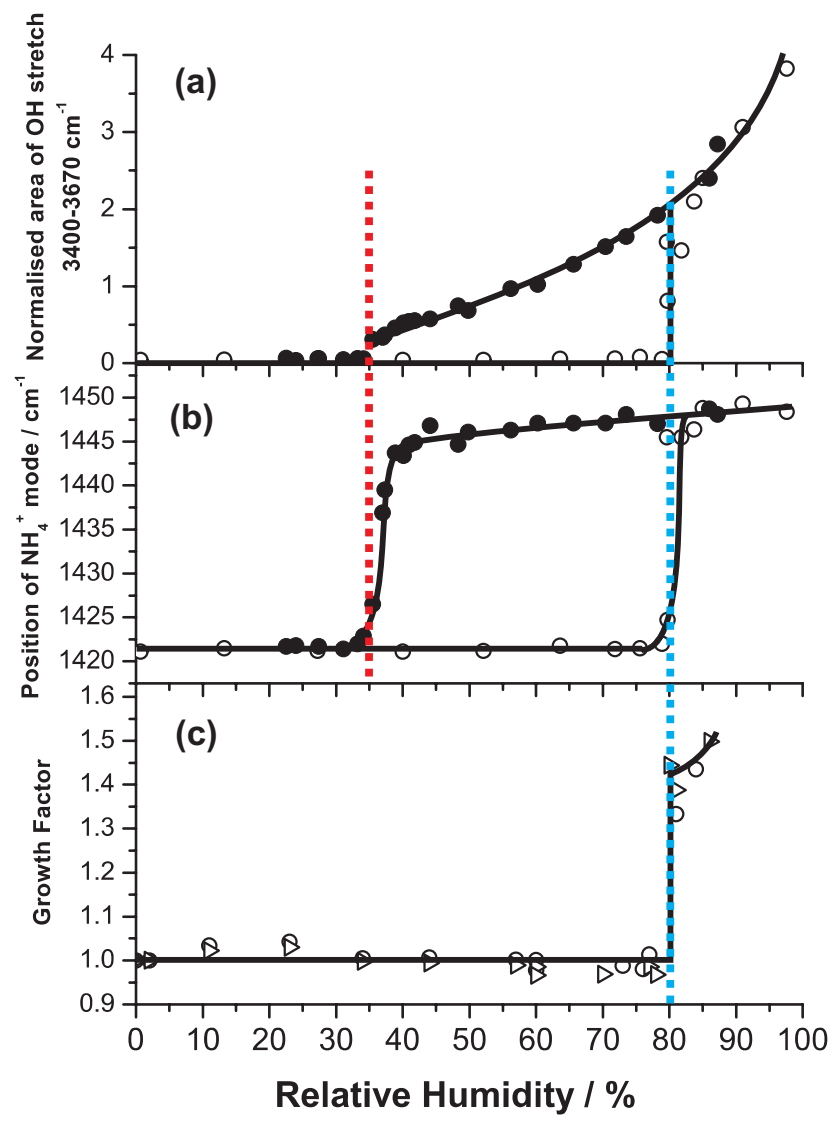

Fig. 3. Water content curve (a) and shifts in $\mathrm{NH}_{4}^{+}$mode (b) for ammonium sulphate aerosol as obtained using FTIR spectroscopy in both deliquescence (open circles) and efflorescence modes (filled circles). Growth curve (c) obtained using the TDMA for both $50 \mathrm{~nm}$ (circles) and $100 \mathrm{~nm}$ (triangles) diameter particles for ammonium sulphate aerosol in deliquescence mode. Dashed blue line, $\mathrm{DRH}=80 \pm 2 \%$; dashed red line, $\mathrm{ERH}=34 \pm 2 \%$. In all cases, the solid lines act as a guide to the eye.

as a dotted red line) with a growth factor, $\mathrm{G}=1.48 \pm 0.02$ at $85 \% \mathrm{RH}$. Errors are estimated from the deviation of the data points from the mean value. These results are in agreement with literature values (Tang and Munkelwitz, 1993; Cziczo et al., 1997; Seinfeld and Pandis, 1998) confirming satisfactory performance of our experimental systems.

\subsection{Water content and phase of humic acid aerosols}

\subsubsection{Single-component humic acid aerosols}

IR spectra obtained at $R H<2 \%$ of both $\mathrm{pH} 4$ and $\mathrm{pH} 9 \mathrm{NaHA}$ aerosols are shown in Fig. 4. Aerosol absorption features have been assigned according to the functional groups known to be present in humic acid (Davis et al., 1999) and are summarised in Table 2. It can be seen from Fig. 4 that the relative size of the absorption mode at $1730 \mathrm{~cm}^{-1}$ increases with 


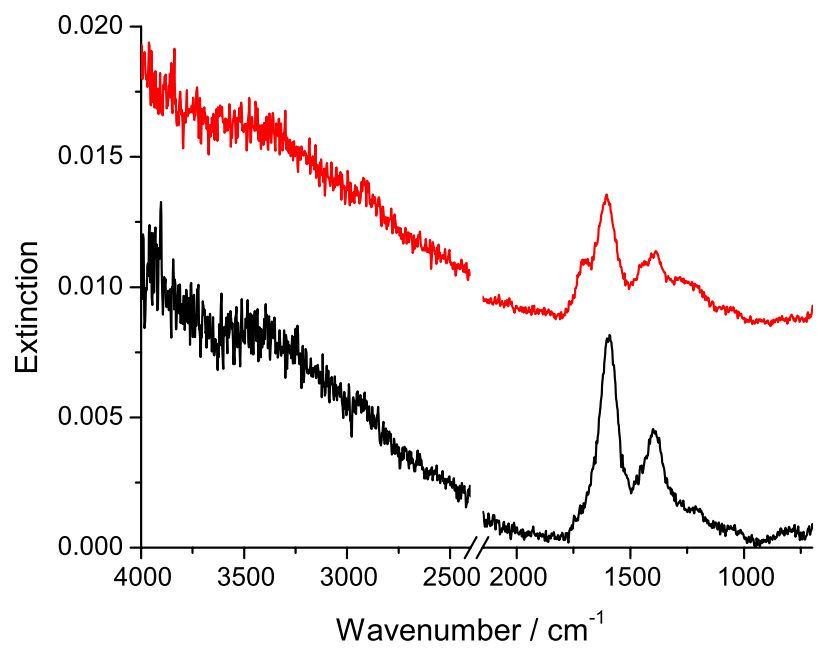

Fig. 4. A comparison of the dry $(R H<2 \%)$ IR spectra obtained for $\mathrm{pH} 9$ (black line) and $\mathrm{pH} 4$ (red line) NaHA aerosols. Spectral features due to $\mathrm{CO}_{2}$ have been removed. Gas-phase water lines have been subtracted and the $\mathrm{pH} 4$ spectrum off-set by 0.08 for clarity.

Table 2. Absorption features seen in the IR spectra of humic acid (Davis et al., 1999).

\begin{tabular}{|c|c|}
\hline Absorption $/ \mathrm{cm}^{-1}$ & Assignment \\
\hline 1730 & $\begin{array}{l}\mathrm{C}=\mathrm{O} \text { from aldehyde, ketone } \\
\text { or carboxylic acid }\end{array}$ \\
\hline 1600 & $\begin{array}{l}\text { Carboxylate antisymmetric stretch } \\
\mathrm{C}=\mathrm{C} \text { (small contribution) }\end{array}$ \\
\hline 1400 & Carboxylate symmetric stretch \\
\hline 1210 & $\mathrm{C}-\mathrm{O}$ stretch \\
\hline \multirow[t]{2}{*}{$2800-3400$} & C-H stretch \\
\hline & $\mathrm{O}-\mathrm{H}$ stretch from $-\mathrm{COH}$ and $-\mathrm{COOH}$ \\
\hline
\end{tabular}

a decrease in $\mathrm{pH}$ as more carboxylic acid groups are protonated.

One major question is whether or not there is liquid water associated with the particles at low $R H(<2 \%)$ as the $\mathrm{OH}$ stretch absorption in condensed-phase water occurs in a similar place to the $\mathrm{OH}$ stretch from alcohol and carboxylic acid groups present in the humic acid. The $\mathrm{OH}$ stretch from - $\mathrm{COH}$ and $-\mathrm{COOH}$ groups in solution occurs in the region 3200-3500 $\mathrm{cm}^{-1}$ (Lin-Vien et al., 1991). Both spectra in Fig. 4 show some absorption at wavenumbers higher than $3500 \mathrm{~cm}^{-1}$ which suggests that there is a small amount of condensed-phase water associated with the particles at $R H<2 \%$. Although the area integrated to represent this condensed-phase water is from $3400-3670 \mathrm{~cm}^{-1}$, the contribution from $-\mathrm{COH}$ and $-\mathrm{COOH}$ in this region is likely to be minimal.

IR spectra of $\mathrm{pH} 9 \mathrm{NaHA}$ aerosol obtained during a deliquescence mode experiment are shown in Fig. 5. Condensed-

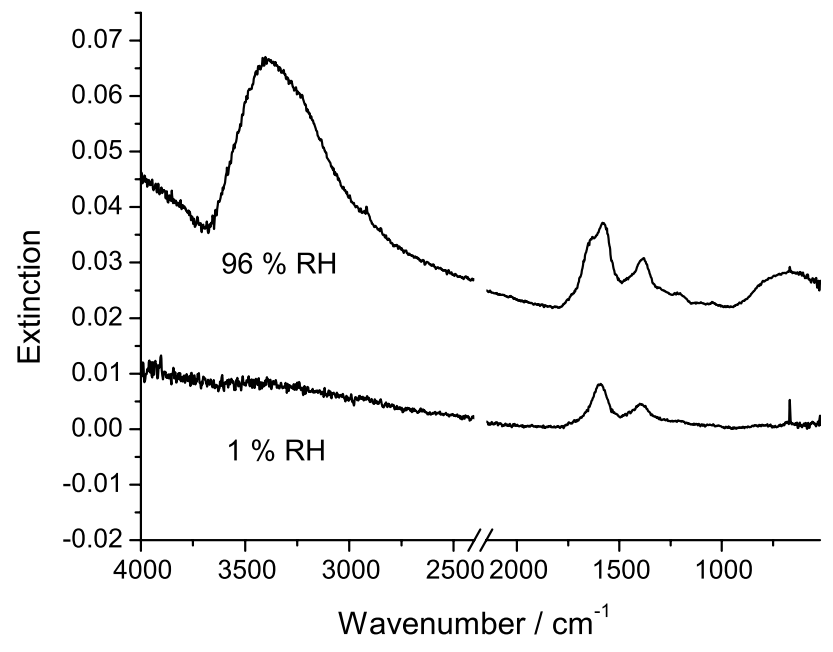

Fig. 5. Infra-red spectra for $\mathrm{pH} 9 \mathrm{NaHA}$ aerosol obtained during a deliquescence mode experiment. Spectral features due to $\mathrm{CO}_{2}$ have been removed. Gas-phase water lines have been subtracted and the top spectrum off-set by 0.02 for clarity.

phase water features at 3450,1640 and $650 \mathrm{~cm}^{-1}$ can be clearly seen in the top spectrum of this figure showing that the particles incorporate much more water at high RH. The water uptake of the humic acid aerosol was analysed quantitatively by integrating the condensed-phase water band due to the $\mathrm{OH}$ stretch between 3400 and $3670 \mathrm{~cm}^{-1}$. Unlike in ammonium sulphate, there is no isolated absorption mode to use for normalisation, so an area was chosen where there are absorption features due to the aerosol but no condensedphase water absorptions, in this case from $1000-1400 \mathrm{~cm}^{-1}$. It should be noted that this area may represent a different aerosol mass for the different humic acid samples and therefore water content data cannot be directly compared.

The water content curves for aerosols produced from $\mathrm{pH} 4$ and pH 9 NaHA and LSHA are shown in Fig. 6 for both efflorescence and deliquescence modes. Although there is some divergence at high $R H$ in the water content curves for the pH 4 and pH 9 NaHA aerosol (Fig. 6b), this is within the experimental uncertainty and the water content curves for both aerosols show similar features with a larger increase in water content with $R H$ at $R H \leq 10 \%$ followed by a more gradual increase in water content. No hysteresis is seen between the efflorescence and deliquescence mode water content curves implying that these aerosols do not show efflorescence and deliquescence behaviour.

\subsubsection{Mixed ammonium sulphate and humic acid aerosols}

The low $R H(<2 \%)$ spectra obtained for aerosols generated from three mixed NaHA and AS solutions are shown in Fig. 7. Features from both the NaHA and the AS components are present. Spectra have been normalised to the height of the sulphate absorption mode at $\sim 1100 \mathrm{~cm}^{-1}$ and, 


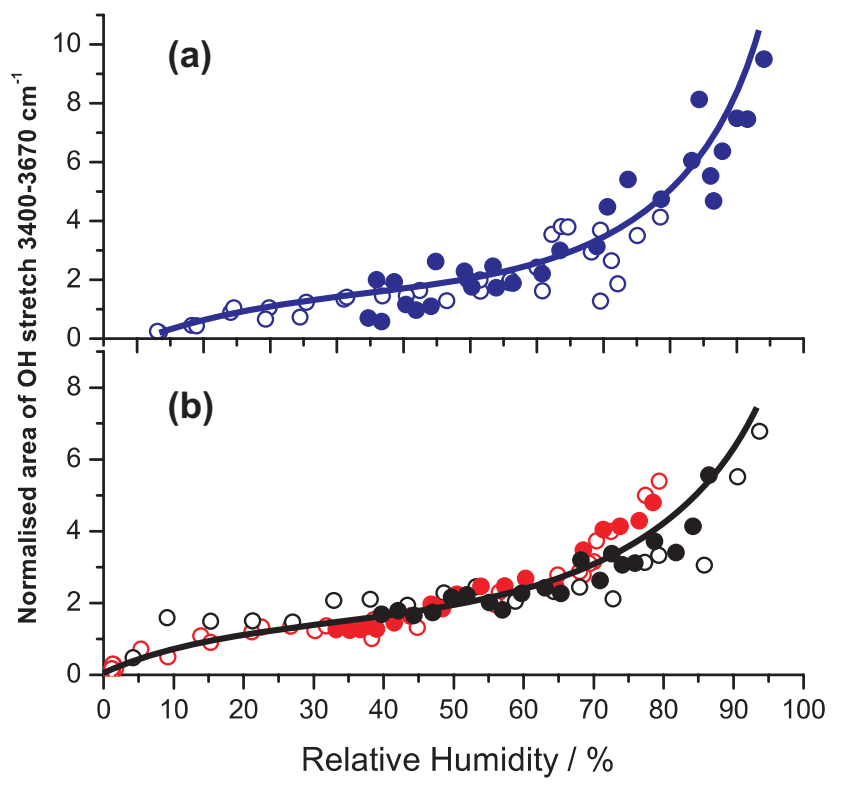

Fig. 6. Water content curves obtained for LSHA (blue symbols), $\mathrm{pH}$ 9 NaHA (black symbols) and pH 4 NaHA (red symbols) aerosols. Data are shown for both deliquescence (open circles) and efflorescence (filled circles) modes. The line acts as a guide to the eye.

as the mass fraction of humic acid is increased, the humic acid absorption features between 1600 and $1700 \mathrm{~cm}^{-1}$ increase in intensity implying that our calculated mass ratios of NaHA:AS are qualitatively correct.

The mixed NaHA and AS aerosols were analysed for both water content and AS phase transitions in both efflorescence and deliquescence modes, as shown in Fig. 8. Experiments were also carried out on a 1:1 LSHA:AS aerosol (Fig. 9). The water content was quantified according to the method used for the single-component ammonium sulphate aerosol with the $\mathrm{OH}$ stretch absorption feature normalised in each case to the area of the sulphate absorption mode $\left(1000-1200 \mathrm{~cm}^{-1}\right)$. It should be noted that this area represents a different total mass of aerosol in each of these cases so the water content of the mixed aerosols cannot be directly compared.

The 1:1 NaHA:AS aerosol shown in Fig. 8 was generated from a $\mathrm{pH} 8$ solution. Experiments were also carried out using a 1:1 NaHA:AS solution acidified to $\mathrm{pH} 3$ by adding $\mathrm{HCl}$. No difference in the water content curves or $\mathrm{NH}_{4}^{+}$mode positions were seen in either deliquescence or efflorescence mode experiments compared with the 1:1 NaHA:AS pH 8 aerosol.

The shift in the position of the $\mathrm{NH}_{4}^{+}$mode was used to determine the crystallization relative humidity $(\mathrm{CRH})$ and deliquescence relative humidity (DRH) for the ammonium sulphate component in the mixed aerosols. These phase changes are summarised in Table 3. This process is not full efflorescence as there is still condensed-phase water associated with the aerosol, therefore the term crystallization is used to de-

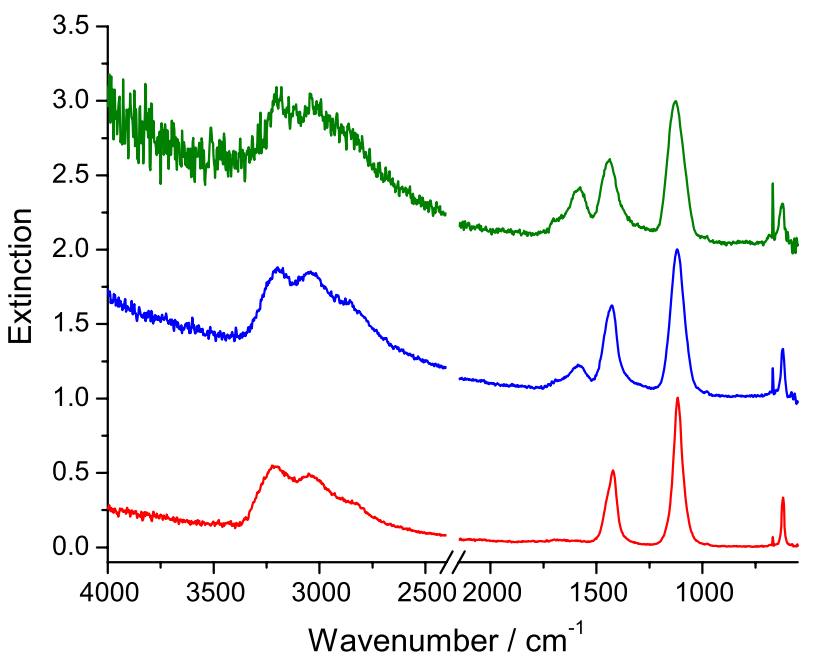

Fig. 7. Dry $(R H<2 \%)$ IR spectra obtained for aerosols generated from three mixed Aldrich humic acid (NaHA) and ammonium sulphate (AS) solutions. Red line, 1:13 NaHA:AS; blue line, 1:1 NaHA:AS; green line, 1.5:1 NaHA:AS. Spectral features due to $\mathrm{CO}_{2}$ have been removed and the spectra normalised to the height of the sulphate absorption mode (at $\sim 1100 \mathrm{~cm}^{-1}$ ). For clarity, gasphase water lines have been subtracted and the top two spectra offset by 0.11 and 0.07 , respectively.

Table 3. Summary of the deliquescence (DRH) and crystallisation $(\mathrm{CRH})$ points observed for the Aldrich humic acid (NaHA), Leonardite standard humic acid (LSHA) and ammonium sulphate (AS) aerosols studied in this work. For the mixed aerosols, the DRH and $\mathrm{CRH}$ values refer to the ammonium sulphate component.

\begin{tabular}{ccc}
\hline Aerosol & CRH / \% & DRH / \% \\
\hline AS & $34 \pm 2$ & $80 \pm 2$ \\
NaHA & n.o. $^{\mathrm{a}}$ & n.o. \\
LSHA & n.o. $^{\mathrm{a}}$ & n.o. \\
1:13 NaHA:AS & $35 \pm 2$ & $77 \pm 2$ \\
1:1 NaHA:AS & $43 \pm 2$ & $73 \pm 2$ \\
1.5:1 NaHA:AS & $33-48$ & $62-75$ \\
1:1 LSHA:AS & $35-45$ & $65-70$ \\
\hline
\end{tabular}

a not observed (n.o.)

scribe the phase transition of the ammonium sulphate component of the aerosol.

Table 3 shows that the DRH of the ammonium sulphate component is lowered from $80 \% \mathrm{RH}$ to between 62 and $77 \%$ $R H$ depending on the amount of humic acid present in the aerosol. The CRH is increased from $34 \% R H$ to between $35 \% R H$ and $48 \% R H$. Again, the magnitude of the increase is dependent on the amount of humic acid present in the aerosols. It should also be noted that the phase transitions are much less abrupt than in the pure ammonium sulphate case and again, this broadening appears to increase with the amount of humic acid present. 

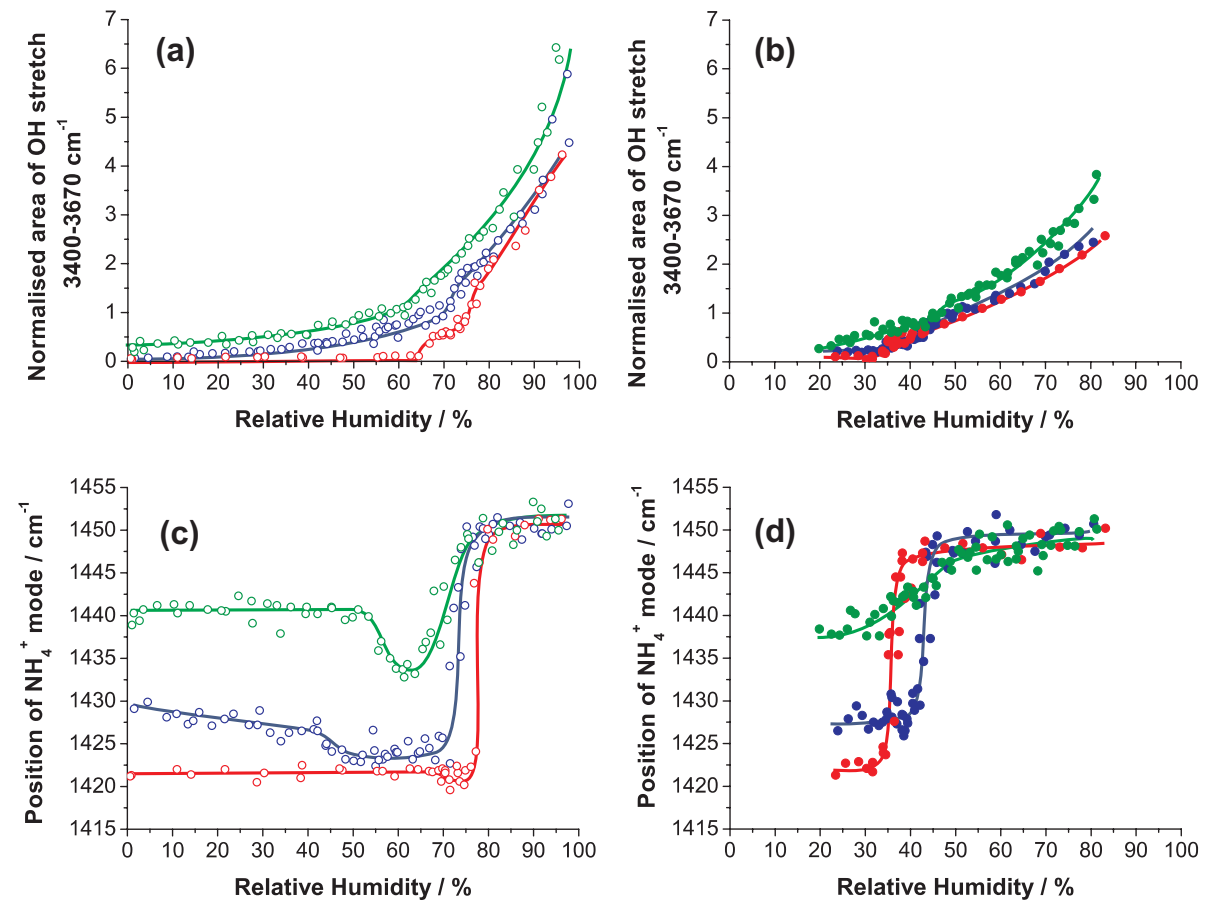

Fig. 8. Water content curves (a, b) and shifts in $\mathrm{NH}_{4}^{+}$mode (c, d) for three mixed Aldrich humic acid (NaHA) and ammonium sulphate (AS) aerosols. Red lines, 1:13 NaHA:AS; blue lines, 1:1 NaHA:AS; green lines, 1.5:1 NAHA:AS. Data are shown for both deliquescence (open circles) and efflorescence (filled circles) modes. The lines act as a guide to the eye.

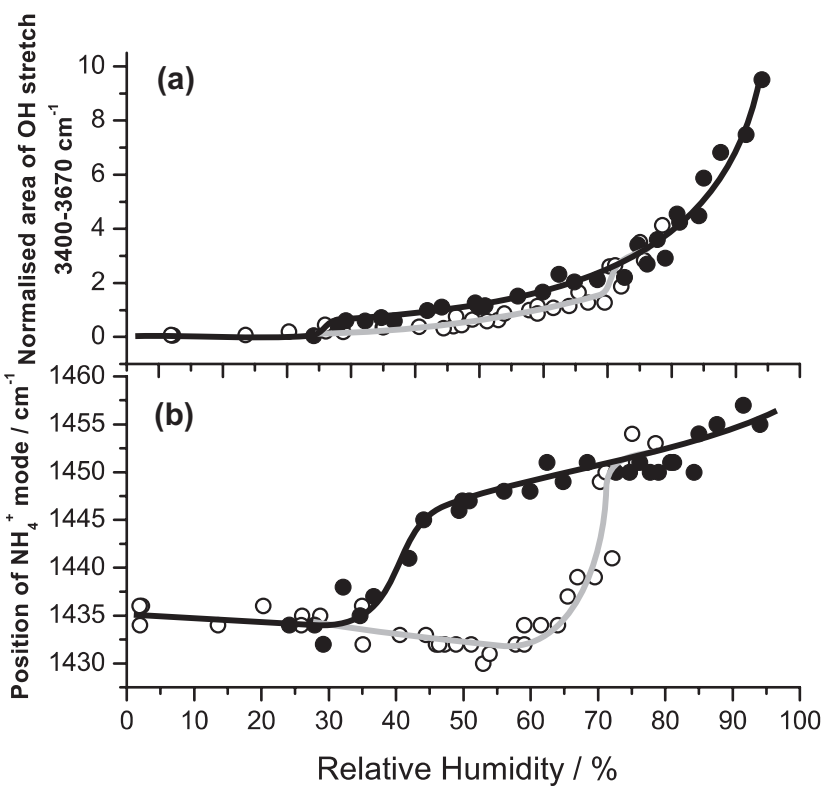

Fig. 9. Water content curve (a) and shifts in $\mathrm{NH}_{4}^{+}$mode (b) for $1: 1$ LSHA:AS aerosol in both deliquescence (open circles) and efflorescence modes (filled circles). The solid lines act as a guide to the eye.
The position of the $\mathrm{NH}_{4}^{+}$mode not only allows the AS phase transitions to be accurately determined, but also gives an insight into the chemical environment present in the aerosol. From Figs. $8 \mathrm{c}$ and $9 \mathrm{~b}$ it can be seen that the position of the $\mathrm{NH}_{4}^{+}$mode is dependent on the amount of humic acid present in the aerosols and is different from that seen at low $R H$ for pure ammonium sulphate aerosol (Fig. 3). From this it may be concluded that the chemical environment of the ammonium ion in the mixed aerosols at low $R H$ must be different from that in crystalline ammonium sulphate. This behaviour was also seen in our previous work on mixed malonic acid and ammonium sulphate aerosols (Braban and $\mathrm{Ab}-$ batt, 2004) where the $\mathrm{NH}_{4}^{+}$mode position was between 1430 and $1435 \mathrm{~cm}^{-1}$ at low $R H$ for mole fractions of malonic acid greater than 0.4 .

There are two possible reasons for the observed shift in $\mathrm{NH}_{4}^{+}$mode position at low $R H$ : a) In both the malonic acid-AS and humic acid-AS mixtures a complex between the carboxylic acid functional groups and the $\mathrm{NH}_{4}^{+}$is forming which gives rise to a different $\mathrm{NH}_{4}^{+}$position; b) The ammonium sulphate has only partially crystallized and the position of the $\mathrm{NH}_{4}^{+}$mode at low $\mathrm{RH}$ reflects an average value of some $\mathrm{NH}_{4}^{+}$in aqueous and some in solid form. The solid and aqueous $\mathrm{NH}_{4}^{+}$modes are both broad so it is not possible to resolve them with our FTIR system. At this stage it is not possible to distinguish between these two explanations although the first explanation may be the more likely as there 
is only a small amount of liquid water associated with the particles at low RH.

In the deliquescence experiments, for all the humic acid and ammonium sulphate mixed aerosols, the position of the $\mathrm{NH}_{4}^{+}$mode was observed to shift to lower wavenumbers at intermediate $R H$ prior to full deliquescence. On deliquescence, the $\mathrm{NH}_{4}^{+}$mode shifted to $1455 \mathrm{~cm}^{-1}$, identical to that observed in aqueous ammonium sulphate. This behaviour could be the result of an ammonium sulphate-humic acid complex converting first to solid ammonium sulphate which then undergoes deliquescence. However, solid ammonium sulphate does not appear to be an intermediate during efflorescence as the $\mathrm{NH}_{4}^{+}$peak is observed to go directly from the aqueous position to that of the (postulated) humic acid-ammonium sulphate complex. If we consider that the observed $\mathrm{NH}_{4}^{+}$shifts are due to partial crystallization, then the shift to lower wavenumber prior to deliquescence would seem to imply the formation of more solid ammonium sulphate. One possible explanation for this is that an increase in water content allows ions in the uncrystallised portion to become more mobile, increasing the probability of collision and crystallization. This is not unlike some inorganic solutions that form glasses if rapidly cooled and then only crystallise upon subsequent slow heating. A larger shift is seen for the 1.5:1 HA:AS aerosol, shown by the green line in Fig. 8c, which may be due to the fact that there is more water associated with these particles or that there is more of the humic acid-ammonium sulphate complex at low RH.

The above discussion highlights the advantages of FTIR in studying different species within an aerosol particle as opposed to bulk properties such as size or mass changes. However, complementary information can also be determined from a consideration of the water content of these aerosols. The water content curves for the 1:1 and 1.5:1 NaHA:AS aerosols (Fig. 8a) and the 1:1 LSHA:AS aerosol (Fig. 9a) show water uptake prior to the deliquescence of the ammonium sulphate component and there is a small but observable inflexion in the water content curves at about the same $R H$ that the $\mathrm{NH}_{4}^{+}$absorption is seen to shift (Fig. 8c).

The water content curves also reveal two phase changes (at $\sim 65 \% R H$ and $\sim 76 \% R H$ ) for the 1:13 NaHA:AS aerosol during a deliquescence mode experiment, shown by the red line in Fig. 8a. This behaviour was found to be reproducible over several experiments carried out using this aerosol composition. The second phase change can be attributed to the deliquescence of the ammonium sulphate component as it corresponds to a shift in the $\mathrm{NH}_{4}^{+}$mode as seen in Fig. 8c.

There are two potential explanations for the first phase change: a) The presence of large amounts of ammonium sulphate promotes the efflorescence of the humic acid component and the phase transition at $65 \% \mathrm{RH}$ is the deliquescence of that humic acid component followed by the deliquescence of the ammonium sulphate component at $76 \% R H$; b) Some sodium sulphate is formed at low $R H$ (this aerosol contains the Aldrich humic acid sodium salt and ammonium sulphate) and this deliquesces at $65 \% R H$. In sodium sulphate aerosol the position of the sulphate absorption mode is observed to depend on the phase of the aerosol (Lebold, 2004). The position of the sulphate mode was determined as a function of $R H$ for the 1:13 NaHA:AS aerosol but it was not possible to discriminate between mode shifts due to $\mathrm{Na}_{2} \mathrm{SO}_{4}$ and AS phase transitions.

The water content curves for the efflorescence mode experiments are shown in Fig. 8b and Fig. 9. The water content at intermediate $R H$ is higher in the efflorescence mode experiments reflecting the fact that the ammonium sulphate component does not effloresce until around $35 \% \mathrm{RH}$. As the particles still retain water after efflorescence, it is harder to see phase changes in the water content curves again showing the advantage of using the position of the $\mathrm{NH}_{4}^{+}$peak to observe phase changes in mixed aerosols including ammonium sulphate.

Both the NaHA and LSHA aerosols used in this work contain $\mathrm{Na}^{+}$which could affect their properties making them somewhat more hygroscopic than had it not been present. However, we have shown that changing the $\mathrm{pH}$ of the solution has no effect on the water content or phase transitions of either the single-component humic acid or mixed ammonium sulphate-humic acid aerosols. Given that within atmospheric aerosol HULIS is also likely to be associated with an electrolyte solution, we believe the results presented here are applicable to a wide range of proxies for atmospheric HULIScontaining particles.

\subsection{Growth of humic acid aerosols}

Growth curves for NaHA and three different mixed NaHA and ammonium sulphate compositions are shown in Fig. 10. The particle hygroscopic growth was found to be independent of the diameter of the originally selected particles (50 or $100 \mathrm{~nm}$ ). This corroborates the TDMA studies of Hameri et al. (2000) who investigated the size dependence of the deliquescence of ammonium sulphate nanoparticles. Hygroscopic growth was found to depend on the aerosol composition and observed phase changes were consistent with the FTIR measurements. It should be noted that the composition of the aerosols particles used in the FTIR experiments differs slightly.

The growth factors at $85 \% R H$ for the five different aerosols studied in this work are summarised in Table 4. The growth of the single-component NaHA aerosol is much less than that of the single-component inorganic salt, ammonium sulphate, with growth factors of $1.16 \pm 0.03$ and $1.45 \pm 0.02$ respectively, at $85 \% R H$. The growth factors for the mixed aerosols are intermediate between those of the single-component aerosols and increase with the amount of ammonium sulphate associated with the aerosols.

For the single-component NaHA humic acid (Fig. 10a), growth was seen over the full range of $R H$ but the change in diameter as a function of $R H$ was not constant. Similar 

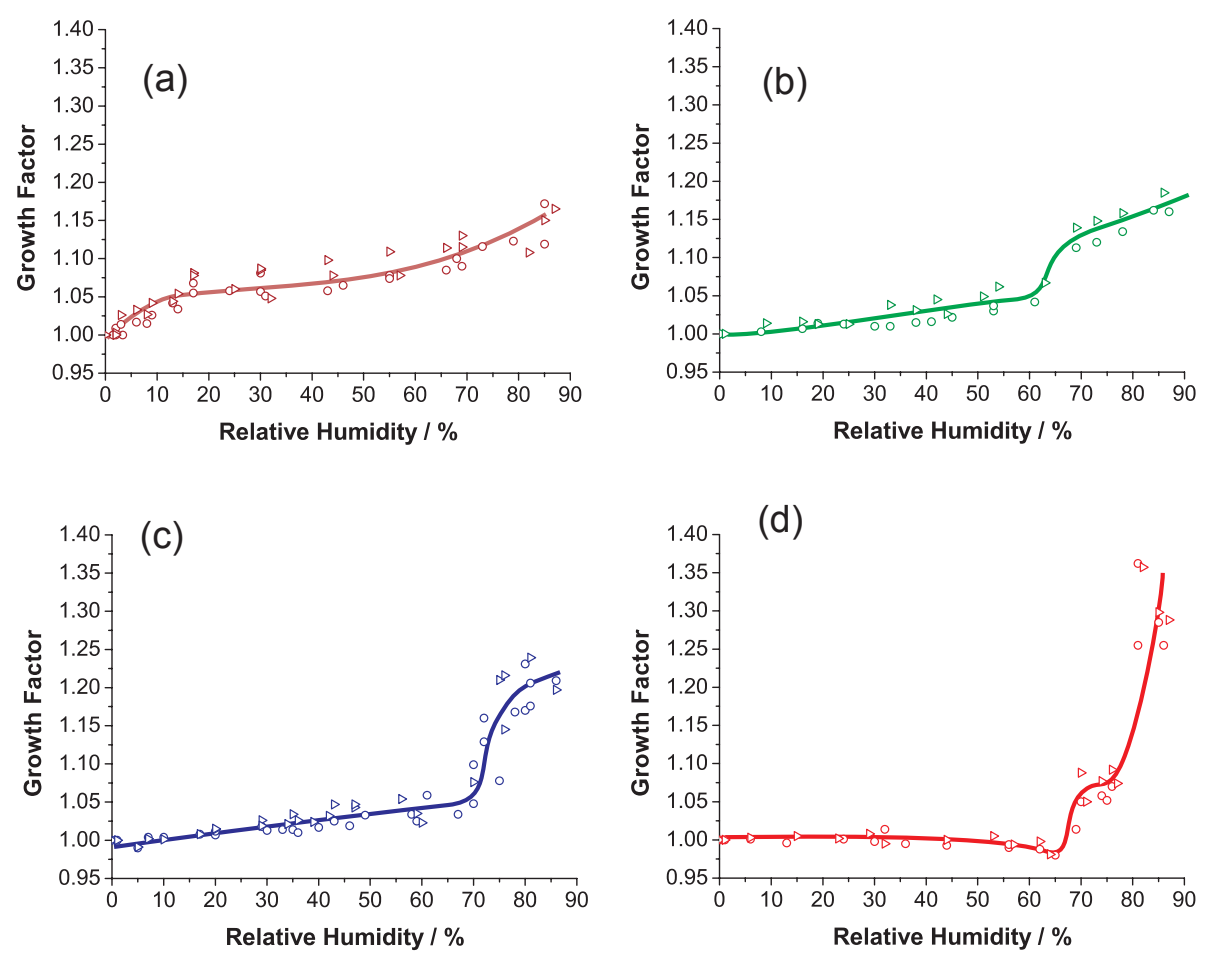

Fig. 10. Growth curves for NaHA (a), 2:1 NaHA:AS (b), 1:1.5 NaHA:AS (c), 1:5 NaHA:AS (d). Data for both $100 \mathrm{~nm}$ (circles) and 50 nm (triangles) diameter particles are shown. The lines act as a guide to the eye.

Table 4. Summary of the growth factors observed for the Aldrich humic acid (NaHA) and ammonium sulphate (AS) aerosols studied in this work. Errors are estimated from deviation of the data from the mean value.

\begin{tabular}{cc}
\hline Aerosol & G at $85 \% R H$ \\
\hline AS & $1.45 \pm 0.02$ \\
1:5 NaHA:AS & $1.33 \pm 0.02$ \\
1:1.5 NaHA:AS & $1.23 \pm 0.03$ \\
2:1 NaHA:AS & $1.17 \pm 0.04$ \\
NaHA & $1.16 \pm 0.03$ \\
\hline
\end{tabular}

behaviour to that seen with the FTIR was observed with a sharp initial increase in diameter with $R H$ from $0-10 \% R H$ followed by a more gradual increase in diameter with $R H$.

For the 2:1 NaHA:AS and 1:1.5 NaHA:AS aerosols (Figs. 10b and c), growth was observed as a function of $R H$ until a sharp size change was observed at a $R H$ consistent with the ammonium sulphate deliquescence seen in the FTIR experiments. For the 2:1 NaHA:AS deliquescence was observed between 60 and $70 \% R H$ and for the 1:1.5 NaHA:AS aerosol at $\sim 73 \% R H$.

The 1:5 HA:AS aerosol (Fig. 10d) shows two phase changes at similar $R H$ to those seen for the 1:13 NaHA:AS aerosol in the FTIR experiments. The rapid increase in diam- eter with $R H$ at $77 \% R H$ can be attributed to deliquescence of the ammonium sulphate component as it is accompanied by a shift in the $\mathrm{NH}_{4}^{+}$mode as seen in the FTIR spectra. For a discussion on the possible explanation for the phase change at $65 \% R H$, see Sect. 3.2.2.

\section{Discussion}

For the first time, two complementary techniques (FTIR spectroscopy and TDMA) have been used in the same study to investigate the phase transitions and growth of aerosols containing humic acid and mixtures of humic acid and ammonium sulphate. The use of FTIR spectroscopy allows unambiguous assignment of AS phase transitions from the shift in the $\mathrm{NH}_{4}^{+}$absorption mode. The position of this mode at low $R H$ also provides evidence for different chemical environments present in the mixed aerosol particles. We have presented the first results from our TDMA experiments which give quantitative values for the growth of the particles with varying $R H$. We find that the humic acid aerosol shows no phase transitions and a much smaller growth factor $(1.16$ at $85 \% R H)$ than inorganic aerosols. The growth factors of the mixed aerosols are intermediate between those of the single-component aerosols.

We have also shown that the presence of humic acid affects the phase transitions of ammonium sulphate aerosol. The DRH of the ammonium sulphate component is lowered 
Table 5. Summary of growth factors at $85 \% \mathrm{RH}$ from the literature for humic and fulvic acid aerosols. The EDB mass growth ratios have been converted to diameter growth ratios assuming an aqueous phase density of $1.72 \mathrm{~g} \mathrm{~cm}^{-3}$ (Chan and Chan, 2003).

\begin{tabular}{lclc}
\hline Paper & Technique & Humic/fulvic acid & G at 85\% RH \\
\hline This work & TDMA & Aldrich humic acid sodium salt (NaHA) & 1.16 \\
\hline Gysel et al. (2004) & TDMA & Aldrich humic acid sodium salt (NaHA) & 1.18 \\
& & Nordic reference fulvic acid (NRFA) & 1.08 \\
& & Nordic reference humic acid (NRHA) & 1.06 \\
\hline Brooks et al. (2004) & TDMA & Pahokee peat reference humic acid (PPRHA) & 1.08 \\
& & Leonardite standard humic acid (LSHA) & 1.03 \\
& & Suwannee river fulvic acid (SRFA) & 1.06 \\
\hline Chan and Chan (2003) & \multirow{2}{*}{ EDB } & Nordic aquatic fulvic acid (NAFA) & 1.16 \\
& & Suwannee river fulvic acid (SRFA) & 1.10 \\
\hline Svenningsson et al. (2005) & TDMA & Suwannee river fulvic acid (SRFA) & 1.05 \\
\hline
\end{tabular}

from $80 \% R H$ to between 62 and $77 \% R H$ dependent on the amount of humic acid present in the aerosol. There is also a noticeable increase in water content below the DRH of the ammonium sulphate component, due to water uptake by the humic acid. The CRH of the ammonium sulphate component is increased from 34\% RH to between 35\% RH (1:13 NaHA:AS) and up to $48 \% R H$ (1.5:1 NaHA:AS), again, dependent on the amount of humic acid.

\subsection{Single-component humic acid aerosols}

\subsubsection{Growth}

There have been several other studies of the phase transitions and growth of humic materials. Table 5 summarises the growth factors at $85 \% R H$ for the single-component humic or fulvic acid aerosols for comparison with our work. Our data are in agreement with other studies supporting the general conclusion that HULIS have smaller growth factors that inorganic aerosols.

The variation in the data is due to the fact that humic and fulvic acids are a complex mixture of many unknown substances and as such, their properties will change slightly depending on the exact isolation procedure. In addition, the presence of a counter ion, such as sodium in the case of the Aldrich humic acid chosen in this work, will affect the hygroscopic growth curves. Indeed, this is very likely to be the reason that the growth factor for the Aldrich humic acid is larger than those for other materials listed in the Table 5. This growth factor could be regarded as an upper limit for growth factors for HULIS though it should be noted that HULIS is likely to be present with some electrolyte solution in atmospheric aerosol.

The growth of the particles at low $R H(\leq 10 \%)$, which is observed in both the FTIR and TDMA experiments is difficult to explain. The extent of growth - of a few $\mathrm{nm}$ - appears to be more than would arise from simply monolayer uptake. Perhaps some degree of structural rearrangement occurs as water is taken up.

\subsubsection{Phase changes}

In our study, we found no evidence for efflorescence or deliquescence in the single-component humic acid aerosols. Similar behaviour was seen in the work by Brooks et al. (2004), Svenningsson et al. (2005), and Chan and Chan (2003). The only study to observe efflorescence and deliquescence behaviour in humic and fulvic acid aerosols was the TDMA study by Gysel et al. (2004). This is also the only other study of the Aldrich Humic acid sodium salt (NaHA). The growth factor at $85 \% R H$ measured by Gysel et al. (2004), is in agreement with our work, however their growth curves differ from ours. Between 65 and 75\% $R H$ they found the mean diameter of the aerosol particles decreased slightly and was accompanied by a broadening of the monodisperse aerosol distribution. They attributed this behaviour to the deliquescence of the particles and similar growth curves were seen for all aerosols studied in their paper. However, this unusual hysteresis behaviour was only observable due to their high instrument resolution and is probably not of atmospheric importance.

Gysel et al. (2004) also studied the efflorescence of these humic and fulvic acids. For the NaHA, the particles did not return to their original diameter during a dehydration experiment, even at $R H<3 \%$. However, efflorescence was observed in the diffusion dryer (residence time $180 \mathrm{~s}, R H<5 \%$ ) before the particles underwent a hydration experiment. During evaporation, the particles had a residence time of the order of seconds $(\sim 8 \mathrm{~s})$, which is significantly shorter than that in the diffusion dryer. It is therefore possible that due to mass transfer limitations, the particles did not have sufficient time to effloresce in their dehydration experiments. Chan and 
Table 6. A comparison of the growth factors for the mixed aerosols, $G_{M}$, at $85 \% R H$ calculated using the ZSR relationship, Eq. (1), and measured with the TDMA for the mixed aerosols studied in this work. Errors in the calculated values for $G_{M}$ are estimated from the errors in the mass ratios.

\begin{tabular}{lcc}
\hline \multirow{2}{*}{ Aerosol } & \multicolumn{2}{c}{$G_{M}$ at $85 \%$ RH } \\
& Calculated & Experimental \\
\hline 1:5 NaHA:AS & $1.39 \pm 0.09$ & $1.33 \pm 0.02$ \\
1:1.5 NaHA:AS & $1.31 \pm 0.06$ & $1.23 \pm 0.03$ \\
2:1 NaHA:AS & $1.24 \pm 0.05$ & $1.17 \pm 0.04$ \\
\hline
\end{tabular}

Chan (2003) found that $60 \mathrm{~min}$ was sufficient to obtain equilibrium measurements in their EDB system. The lack of hysteresis behaviour seen in our work for the NaHA may therefore be explained by the fact that the conditions in our dryer (residence time $\sim 30$ s) were not sufficient to completely effloresce the particles. Nevertheless, our measurements are in general agreement with others showing that efflorescence does not occur readily with these species.

\subsection{Mixed humic acid and ammonium sulphate aerosols}

\subsubsection{Phase changes}

Previous studies of the effect of smaller organics (e.g. dicarboxylic acids) on the phase transitions of inorganic aerosols have shown a decrease in both the ERH and DRH (Braban and Abbatt, 2004; Marcolli et al., 2004; Parsons et al., 2004). The magnitude of the change depends on both the type of organic and the mole fraction present in the particles, with the strongest effects apparent when the species are present in roughly equal ratios. The decrease in DRH seen in our work is in line with other measurements, and to be expected based on the thermodynamics of mixed aerosols (Tang, 1976). Parsons et al. (2004) have used optical microscopy to look at the deliquescence point of ammonium sulphate particles containing fulvic acid and found a little variation in the DRH with the amount of FA present. The thermodynamic models used in their work predict a decrease in DRH with the amount of fulvic acid but due to the large molecular weight of FA and hence small mole fractions of FA studied, this decrease was within the errors of their measurements.

The increase in the CRH for the ammonium sulphate component is unusual having only been reported previously in systems where heterogeneous nucleation of the solid was induced by the presence of an imbedded insoluble particle (Han et al., 2002). The only other study of humic or fulvic acids that considered their effect on the crystallisation of inorganic aerosols is an EDB study by Chan and Chan (2003). In this paper, they state that the fulvic acids have little effect on the $\mathrm{CRH}$ of the inorganics but quote $\mathrm{CRH}$ values of $39.8-43.6 \% R H$ and $38.1-41.5 \% R H$ for the two mixed ful- vic acid-ammonium sulphate aerosols. This is higher than the generally accepted CRH for ammonium sulphate and in agreement with our data. It is possible that the increase in CRH of ammonium sulphate with the addition of humic or fulvic acid is because it is not pure ammonium sulphate that is crystallizing, but an ammonium sulphate-humic acid complex as discussed in Sect. 3.2.2. Alternatively, we can not rule out that heterogeneous nucleation is not occurring, via very small particles that passed through the filters used to prepare the solutions.

\subsubsection{Growth}

Brooks et al. (2004) and Chan and Chan (2003) have considered the effect of humic and fulvic acids on the growth of inorganic aerosol particles using HTDMA and EDB, respectively. The conclusions from both these studies are that the mixed aerosols take up less water at high $R H$ compared with the pure inorganic aerosols. This general conclusion is in agreement with the results we have presented in Table 4. Brooks et al. (2004) show that this can be modeled assuming the two components take up water independently whereas Chan and Chan (2003) find that their mixed fulvic acid-ammonium sulphate have enhanced water uptakes compared with models which treat the components as noninteracting.

Using a similar approach to Brooks et al. (2004), we have calculated the hygroscopic growth factor, $G_{M}$, of our mixed aerosols at $85 \% R H$ using Eq. (1);

$G_{M}=\left(\epsilon_{O} G_{O}^{3}+\epsilon_{I N} G_{I N}^{3}\right)^{\frac{1}{3}}$

where $G_{O}$ is the hygroscopic growth factor of the organic particles, $G_{I N}$ is the hygroscopic growth factor of the inorganic particles, $\epsilon_{O}$ the organic volume fraction and $\epsilon_{I N}$ the inorganic volume fraction. This expression assumes that the inorganic and organic components take up water independently, i.e. the Zvanovskii-Stokes-Robinson (ZSR) assumption, and that the volumes are additive (Seinfeld and Pandis, 1998).

To determine the volume fractions, our mass ratios were converted to volume ratios using densities of $1.77 \pm 0.01 \mathrm{~g}$ $\mathrm{cm}^{-3}$ and $1.1 \pm 0.1 \mathrm{~g} \mathrm{~cm}^{-3}$ (Sigma Aldrich Technical Services) for the ammonium sulphate and humic acid components, respectively. Our calculated and experimental growth factors at $85 \% R H$ are summarised in Table 6. Although the calculated values are generally higher than the experimental values, the results are within experimental error. Our growth data for the mixed aerosols can therefore be modeled assuming the organic and inorganic fractions are non-interacting, a conclusion which is in agreement with that of Brooks et al. (2004). 


\section{Atmospheric implications}

Together with some other recent studies of mixed organicinorganic particles, for example (Braban and Abbatt, 2004; Marcolli et al., 2004; Prenni et al., 2003; Choi and Chan, 2002), we have shown that the presence of organics in atmospheric aerosol will change properties such as phase transitions and hygroscopic growth compared with simple inorganic aerosols. In particular, we find that deliquescence of mixed particles occurs at somewhat lower relative humidities than for the single-component inorganic, ammonium sulphate. The efflorescence behaviour varies from system to system. For the small water soluble diacids, efflorescence of ammonium sulphate is greatly suppressed when mixed in roughly equal proportions (Braban and Abbatt, 2004; Parsons et al., 2004). However, in this work the efflorescence points are increased, perhaps because a different chemical species - a complex between the polyacids and ammonium is forming. Indeed, it is this latter suggestion, that there may be strong chemical interactions occurring between the ammonium and the HULIS materials that is the most novel aspect of this work, and one that can not be observed by TDMA or EDB observations. Additional studies are ongoing in our laboratory involving NMR analysis to better substantiate this suggestion.

These changes in the behaviour of the mixed systems compared to organics alone will affect the optical properties of the aerosols and their ability to act as CCN. In view of the importance of sulphate in radiative forcing calculations, it is important to take modifications due to organics into account in climate models. In addition, given that we have shown that there is more water associated with mixed particles at intermediate and low RH, this may have impacts on the reactivity of these particles especially towards reactions involving water such as $\mathrm{N}_{2} \mathrm{O}_{5}$ hydrolysis. This is the subject of a forthcoming research paper. ${ }^{1}$

To date, the different humic materials that have been used in laboratory studies of this type have all behaved in a qualitatively similar manner, both with respects to their hygroscopic growth and phase transitions. This gives some confidence that an appropriate surrogate for atmospheric HULIS can be developed. Indeed, the similarity in the observed behavior is most likely arising because, while different humic and fulvic materials may have different carbon backbone structures, they are all likely to have similar oxygenated functional groups, i.e. those groups that drive hygroscopic behavior. The next step in studies of this type is to better define the formation mechanisms of HULIS in atmospheric aerosols, whether they be via condensation and polymerization reactions of carbonyl-containing species, cloud process-

\footnotetext{
${ }^{1}$ Badger, C. L. and Griffiths, P. T. and George, I. and Abbatt, J. P. A. and Cox, R. A.: Reactive uptake of $\mathrm{N}_{2} \mathrm{O}_{5}$ by aerosol particles containing mixtures of humic acid and ammonium sulphate, J. Phys. Chem. A, submitted, 2006.
}

ing or heterogeneous oxidation, and to then study the hygroscopic properties in the laboratory of materials formed in this manner.

Acknowledgements. C. L. Badger, P. T. Griffiths and C. F. Braban acknowledge funding from NERC. C. L. Badger also thanks St Catharine's College, Cambridge for a travel grant. Financial support for the FTIR experiments was provided by NSERC and Canada Foundation for Innovation and for the TDMA work by NERC grant NER/B/S/2002/00406. The authors also wish to thank M. Gysel, P. DeMott, C. K. Chan, and B. Svennginsson for useful discussions and permission to quote the data shown in Table 5.

Edited by: Y. Rudich

\section{References}

Baltensperger, U., Kalberer, M., Dommen, J., Paulsen, D., Alfarra, M. R., Coe, H., Fisseha, R., Gascho, A., Gysel, M., Nyeki, S., Sax, M., Steinbacher, M., Prevot, A. S. H., Sjögren, S., Weingartner, E., and Zenobi, R.: Secondary organic aerosols from anthropogenic and biogenic precursors, Faraday Discuss., 130, 265-278, 2005.

Braban, C. F. and Abbatt, J. P. D.: A study of the phase transition behavior of internally mixed ammonium sulfate-malonic acid aerosols, Atmos. Chem. Phys., 4, 1451-1459, 2004.

Braban, C. F., Carroll, M. F., Styler, S. A., and Abbatt, J. P. D.: Phase transitions of malonic and oxalic acid aerosols, J. Phys. Chem. A, 107, 6594-6602, 2003.

Brooks, S. D., DeMott, P. J., and Kreidenweis, S. M.: Water uptake by particles containing humic materials and mixtures of humic materials with ammonium sulfate, Atmos. Environ., 38, 18591868, 2004.

Chan, M. N. and Chan, C. K.: Hygroscopic properties of two model humic-like substances and their mixtures with inorganics of atmospheric importance, Environ. Sci. Technol., 37, 5109-5115, 2003.

Choi, M. Y. and Chan, C. K.: The effects of organic species on the hygroscopic behaviors of inorganic aerosols, Environ. Sci. Technol., 36, 2422-2428, 2002.

Clegg, S. L., Seinfeld, J. H., and Brimblecombe, P.: Thermodynamic modelling of aqueous aerosols containing electrolytes and dissolved organic compounds, J. Aerosol Sci., 32, 713-738, 2001.

Cziczo, D. J., Nowak, J. B., Hu, J. H., and Abbatt, J. P. D.: Infrared spectroscopy of model tropospheric aerosols as a function of relative humidity: Observation of deliquescence and crystallization, J. Geophys. Res. - Atmos., 102, 18 843-18 850, 1997.

Davis, W. M., Erickson, C. L., Johnston, C. T., Delfino, J. J., and Porter, J. E.: Quantitative Fourier transform infrared spectroscopic investigation of humic substance functional group composition, Chemosphere, 38, 2913-2928, 1999.

Fuzzi, S., Decesari, S., Facchini, M. C., Matta, E., Mircea, M., and Tagliavini, E.: A simplified model of the water soluble organic component of atmospheric aerosols, Geophys. Res. Lett., 20, 4079-4082, 2001.

Gysel, M., Weingartner, E., Nyeki, S., Paulsen, D., Baltensperger, U., Galambos, I., and Kiss, G.: Hygroscopic properties of 
water-soluble matter and humic-like organics in atmospheric fine aerosol, Atmos. Chem. Phys., 4, 35-50, 2004.

Hameri, K., Vakeva, M., Hansson, H. C., and Laaksonen, A.: Hygroscopic growth of ultrafine ammonium sulphate aerosol measured using an ultrafine tandem differential mobility analyzer, J. Geophys. Res. - Atmos., 105, 22 231-22 242, 2000.

Han, J. H., Hung, H. M., and Martin, S. T.: Size effect of hematite and corundum inclusions on the efflorescence relative humidities of aqueous ammonium nitrate particles, J. Geophys. Res. Atmos., 107, 4086, doi:10.1029/2001JD001054, 2002.

Kalberer, M., Paulsen, D., Sax, M., Steinbacher, M., Dommen, J., Prevot, A. S. H., Fisseha, R., Weingartner, E., Frankevich, V., Zenobi, R., and Baltensperger, U.: Identification of polymers as major components of atmospheric organic aerosols, Science, 303, 1659-1662, 2004.

Kanakidou, M., Seinfeld, J. H., Pandis, S. N., Barnes, I., Dentener, F. J., Facchini, M. C., Van Dingenen, R., Ervens, B., Nenes, A., Nielsen, C. J., Swietlicki, E., Putaud, J. P., Balkanski, Y., Fuzzi, S., Horth, J., Moortgat, G. K., Winterhalter, R., Myhre, C. E. L., Tsigaridis, K., Vignati, E., Stephanou, E. G., and Wilson, J.: Organic aerosol and global climate modelling: a review, Atmos. Chem. Phys., 5, 1053-1123, 2005.

Lebold, T.: FTIR-spectroscopic investigations of model tropospheric aerosols, ERASMUS project report, University of Cambridge, 2004.

Limbeck, A., Kulmala, M., and Puxbaum, H.: Secondary organic aerosol formation in the atmosphere via heterogeneous reaction of gaseous isoprene on acidic particles, Geophys. Res. Lett., 30, 1996, doi:10.1029/2003GL017738, 2003.

Lin-Vien, D., Colthup, N. B., Fateley, W., and Grasselli, J.: Infrared and Raman characteristic frequencies of organic molecules, Academic Press Inc., San Diego, 1991.

Marcolli, C., Luo, B. P., and Peter, T.: Mixing of the organic aerosol fractions: Liquids as the thermodynamically stable phases, J. Phys. Chem. A, 108, 2216-2224, 2004.

McFiggans, G., Rami Alfarra, M., Allan, J., Bower, K. N., Coe, H., Cubison, M., Topping, D., Williams, P., Decesari, S., Facchini, M. C., and Fuzzi, S.: Simplification of the representation of the organic component of atmospheric particulates, Faraday Discuss., 130, 341-362, 2005.
Parsons, M. T., Knopf, D. A., and Bertram, A. K.: Deliquescence and crystallization of ammonium sulfate particles internally mixed with water-soluble organic compounds, J. Phys. Chem. A, 108, 11 600-11 608, 2004.

Prenni, A. J., De Mott, P. J., and Kreidenweis, S. M.: Water uptake of internally mixed particles containing ammonium sulfate and dicarboxylic acids, Atmos. Environ., 37, 4243-4251, 2003.

Puxbaum, H., Rendl, J., Allabashi, R., Otter, L., and Scholes, M. C.: Mass balance of the atmospheric aerosol in a South African subtropical savanna (Nylsvley, May 1997), J. Geophys. Res. - Atmos., 105, 20 697-20 706, 2000.

Reischl, G. P.: Measurement of ambient aerosols by the differential mobility analyzer method - concepts and realization criteria for the size range between $2 \mathrm{~nm}$ and $500 \mathrm{~nm}$, Aerosol Sci. Technol., 14, 5-24, 1991.

Seinfeld, J. H. and Pandis, S. N.: Atmos. Chem. Phys.: From Air Pollution to Climate Change, Wiley, New York, 1998.

Svenningsson, B., Rissier, J., Swietlicki, E., Mircea, M., Bilde, M., Facchini, M. C., Decesari, S., Fuzzi, S., Zhou, J., Mønster, J., and Rosenørn, T.: Hygroscopic growth and critical supersaturations for mixed aerosol particles of inorganic and organic compounds of atmospheric relevance, Atmos. Chem. Phys. Discuss., 5, 2833-2877, 2005.

Tang, I. N.: Phase transformation and growth of aerosol particles composed of mixed salts., J. Aerosol Sci., 7, 361-371, 1976.

Tang, I. N. and Munkelwitz, H. R.: Composition and temperaturedependence of the deliquescence properties of hygroscopic aerosols, Atmos. Environ., 27, 467-473, 1993.

Topping, D. O., McFiggans, G. B., and Coe, H.: A curved multicomponent aerosol hygroscopicity model framework: Part 2 Including organic compounds, Atmos. Chem. Phys., 5, 1223 $1242,2005$.

Winklmayr, W., Reischl, G. P., Lindner, A. O., and Berner, A.: New electromobility apectrometer for the measurement of aerosol size distributions in the size range from 1 to $1000 \mathrm{~nm}$, J. Aerosol Sci., 22, 289-296, 1991. 